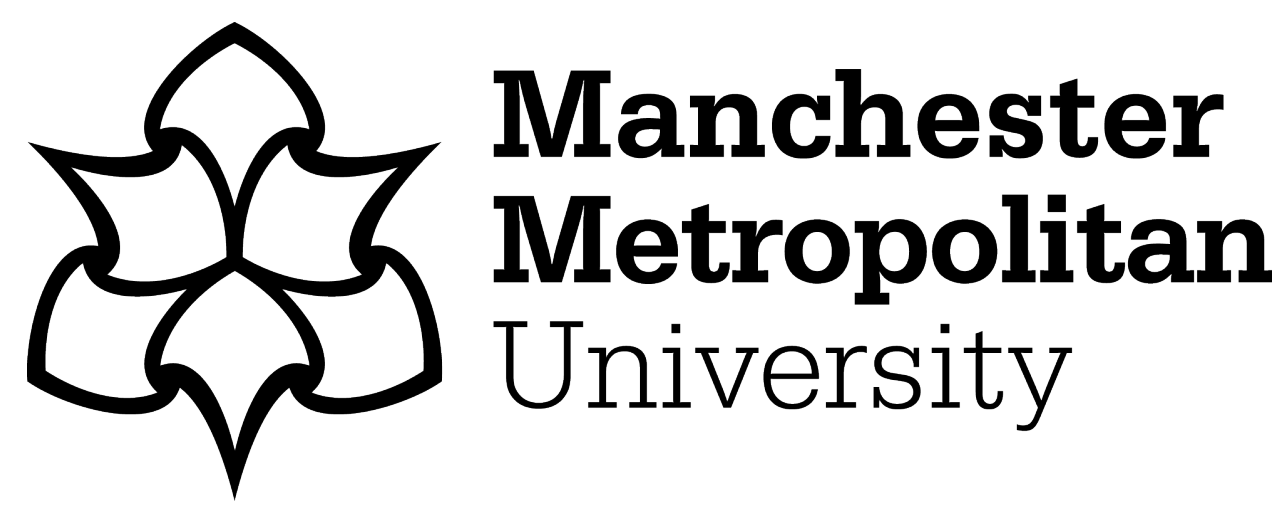

Rayner, Stephen, Lord, Janet ORCID logoORCID: https://orcid.org/00000002-3957-9529, Parr, Elizabeth and Sharkey, Rachel (2015) 'Why has my world become more confusing than it used to be?' Professional doctoral students reflect on the development of their identity. Management in Education, 29 (4). pp. 158-163. ISSN 0892-0206

Downloaded from: https://e-space.mmu.ac.uk/625299/

Version: Accepted Version

Publisher: SAGE Publications

DOI: https://doi.org/10.1177/0892020614567247

Please cite the published version 


\section{Why has my world become more confusing than it used to be? Professional doctoral students reflect on the development of their identity}

\section{Abstract}

This paper reports on research into the experience of professional doctoral students and is written by the students themselves. We, the authors, are currently studying for the Doctorate in Education at the University of Manchester. We place our work in the context of recent empirical research into the development of doctoral student identity, noting that these literatures are usually authored by programme directors and supervisors. Using a theoretical approach based on the work of Etienne Wenger, we examine how the aims and curriculum of our programme interplay with our professional learning. In interviews with our cohort of students, we explore the complexity and non-linearity of learning. We do not find a simple progression from practitioner to researcher, but a fluid and complex relationship between those two identities. We consider the extent to which Wenger's modes of identification are a useful conceptual tool for understanding this interplay and for theorising about our findings. We conclude that there is further scope for the development of our theoretical framework by drawing on other scholarly work on identity development and reflexivity.

\section{Key words}

Professional doctorates, professional learning, identity, Wenger 


\section{Introduction}

The authors of this paper, professional doctoral students at the University of Manchester, have experienced significant changes in our professional identities as we have progressed through the programme. We are interested in the relationship between these changes and our pedagogic, discursive and social experiences as learners. We aim through this enquiry to conceptualise the changes, to understand better the symbiotic relationship between our identities as researchers and as practitioners, and to contribute our findings to the Manchester Institute of Education's annual review of its Doctorate in Education (EdD) programme.

Our research questions are:

1. How significant is each of the range of activities that form the Manchester EdD programme in supporting students' academic and professional development?

2. What is students' experience of the "peer support network" that is one of the stated aims of the programme?

3. How might the programme be reviewed so that it is more effective in meeting the needs of a diverse cohort of students?

In this paper we review some of the relevant literatures, including work on the development of identity and empirical studies of professional doctorates. We use these literatures to develop a conceptual framework based on Wenger's idea of a Landscape of Practice (2010), which informs our thinking and our methodological approach. In our methods section, we discuss interviews and other techniques for eliciting narratives from the participants. Having set out and analysed our findings, 
we draw some tentative conclusions about the transitions and development in the identity of professional doctorate students and about the importance of reflexivity in constructing a social and professional identity.

The programme director and academic staff have supported this research as a contribution to the professional review of the programme. The Head of the Manchester Institute of Education has consented to the naming of our institution in this article. Pseudonyms are used for the names of participants.

\section{Literatures, empirical and theoretical}

There is a wealth of empirical research into the development of doctoral student identity. Some of the papers presented at the 2014 UK Council for Graduate Education International Conference on Professional Doctorates, for example, take an evaluative approach to curriculum and pedagogy, seen from the viewpoint of the supervisory team (Pilkington, 2014; Poultney, 2014). Others explore the perceptions of the students themselves on their learning, using evaluation forms or reflective diaries (Ellis and Robb, 2014; Mills and Black, 2014; Sanders, 2014). A third group considers more closely the motivation of students embarking on a professional doctorate programme, including their aspirations to employability or to be "paraacademics". This group looks at the constraints posed by the professional settings that students come from, and at which groups take the longest to complete their doctoral studies (Hawkes, 2014; Taylor, 2014). Only one of the papers at that conference (Lord et al, 2014) is written and presented by the doctoral students 
themselves. This article is an extended description of the research presented in that conference paper.

The metaphor of the "journey" is a recurring theme in empirical work about the development of doctoral students (for example Scott et al, 2004; Barnacle and Newburn, 2010; Pratt et al, 2013; Rhodes, 2014). Frequently that journey has three stages. In an interview, one of our programme supervisors summarised those three stages as "get in, get on, get out". More elegantly, the three stages have been described by Rhodes (2014) as:

a simple linear three-stage process of participant acculturation, assimilation and actualisation as they address the intended transformation from practitioner to researcher (Rhodes, 2014:5).

Taylor (2007) prefers the terms "Conformity", "Capability", and "Becoming and Being", referred to explicitly as Levels 1, 2 and 3 (Taylor, 2007:162). The doctoral student begins at the lowest level with Conformity:

knowing about research, ... within the traditional apprenticeship model of doctoral education; that is, a transmission approach with the passing on by university experts to novices of technical expertise (Taylor, 2007:161). Next, at Level 2:

Capability focuses on students' individual activity, experience, skills and techniques; in other words, on "doing" research. Research is seen as an intervention, with a view to improving practice in one's own personal context (Taylor, 2007:162).

Finally, at the top level, there is Becoming and Being: 
... based on a deeper reflection that brings about the development of personal identity for the student and change in professional practice in the wider sense as the practitioner leads high level development and change on an institutional basis (Taylor, 2007:162).

For Hall and Burns (2009), doctoral students begin by acquiring "tools of doing (skills for research)" and progress to having "tools of being (human sensibilities and identity formation)". Participants:

must go beyond curriculum as a mechanism for transmitting skill sets and content knowledge to conceiving of curriculum as an explicit socialization project in which careful attention is paid to social, cultural and intellectual diversity (Hall and Burns, 2009:64-65).

Our own discussions as reflective researchers have led us to question, however, whether the process of identity development may be too complex to be characterised simply as a journey from $A$ (competence as a practitioner) to $B$ (competence as an academic scholar); a journey on which, as Taylor (2007) suggests, it is not until the final stage that identity development takes place, and where "leading change on an institutional basis" is the goal. We consider instead whether there is:

a rich variation in multiple formative activities that are experienced as contributing to a developing identity as an academic, with many lying outside formal and semi-formal aspects of the doctorate (McAlpine et al, 2009:97). 
To propose a more comprehensive understanding of the development of professional doctoral student identities, we use Wenger's metaphor of a Landscape of Practice (2010) as an underpinning theory. By turning to Wenger's social perspective on professional learning, we begin to understand in more detail the transitions, adjustments and challenges that doctoral students experience.

Wenger $(1998,2010)$ understands professional occupations such as teaching as being a complex landscape of several communities of practice, all involved not only in practising the occupation but also in other dimensions such as research and regulation. Wenger (2010) suggests that as each has its own regulations, routines, language and histories, it is at the boundaries of these communities of practice that innovation and new thinking happen. Boundaries occur when communities of practice within the landscape do not have shared processes, histories or regulations and are therefore potential sites of confusion, challenge or differences. This is to say that the boundaries between practices can be harmonious, collaborative and filled with potential for new thinking. Or they can be points of conflict, difference and competing practices. Boundary encounters and crossings are an essential aspect of understanding a Landscape of Practice.

In journeying through the landscape, professional identity both shapes and is shaped by the landscape itself. The routines, practices, regimes of competence and boundaries form part of who professionals are and how they understand the world around them. Their identity embodies their experience within it and their journey within and between the communities of practice. When inhabiting a Landscape of Practice, it is essential to distinguish between distinct modes of identification that 
position learning and the changing identity. Each of these modes operates inside practices as well as across boundaries:

Engagement: This is the most immediate relation to a practice-engaging in activities, doing things, working alone or together, talking, using and producing artefacts. Engagement gives us direct experience of regimes of competence, whether this experience is one of competence or incompetence and whether we develop an identity of participation or nonparticipation.

Imagination: As we engage with the world we are also constructing an image of the world that helps us understand how we belong or not. We use such images of the world to locate and orient ourselves, to see ourselves from a different perspective, to reflect on our situation, and to explore new possibilities.

Alignment: Our engagement in practice is rarely effective without some degree of alignment with the context-making sure that activities are coordinated, that laws are followed, or that intentions are communicated. Note that the notion of alignment here is not merely compliance or passive acquiescence; it is not a one-way process of submitting to external authority or following a prescription. Rather it is a two-way process of coordinating perspectives, interpretations, actions, and contexts so that action has the effects we expect. (Wenger, 2010:184-185)

These different modes of identification are ways to make sense of both the landscape and our position in it. All three can result in identification or disidentification, but with different qualities and potentials for locating ourselves in the 
landscape. Wenger states that "Through engagement, but also imagination and alignment, our identities come to reflect the landscape in which we live and our experience of it. Identity becomes a system, as it were" (Wenger, 2010:185). In this Wenger suggests that the development of identity may indeed be a trajectory, but it is also a nexus of multi-membership.

We considered that Wenger's concept of moving in a Landscape of Practice between engagement, imagination and alignment related well to the research we conducted into the EdD programme. It helped us to conceptualise our experience as professional doctorate students. We therefore identified the activities that had been part of the two-year introductory programme, whether specifically mentioned in the programme handbook or advised and encouraged by supervisors in taught sessions and tutorials. We grouped the activities against the "modes" of Engagement, Imagination and Alignment, as shown in Table 1:

Insert Table 1 here

\section{Methods}

Ten of the fourteen students who began the Doctorate in Education programme at the University of Manchester in 2011 agreed to participate in this research. We discussed our proposal with the Programme Director, who supported the research as a contribution to programme review. He and the other two main supervisors also consented to be interviewed at a later stage. 
We conducted semi-structured interviews with the doctoral students, beginning with a card sort. On the cards we placed the sixteen activities listed in Table 1 above. We mixed the cards, without showing the mode of identification to which each related. We asked participants to categorise the activities as being most important, somewhat important or least important in the development of their professional identity. As they positioned the cards, we asked them to comment on their thinking and if necessary to ask for clarification of the meaning of the text. We then asked participants how well the taught programme had helped them to develop those that they considered important.

Later in the interview we showed participants our construction of Wenger's Landscape of Practice and asked for their view of it, and particularly of our suggestion that there might be a progression through engagement, imagination and alignment. We asked these final questions:

1. Apart from what is on the cards, what have you learned from the supervisory team? How has this influenced the development of your identity?

2. The aims of the programme include "creating an invaluable peer support network". How has it worked for you, what have you brought to it, and what have you taken from it?

\section{Analysis}

Following the interviews with participants, we conducted a thematic analysis of the card sort. Each card was allocated a score based on the participant's judgment as 
to its importance to them. We refined the data by focussing on the top five "most important" activities for each participant. This resulted in a rank order for activities in terms of their importance as judged by participants (Table 2).

Insert Table 2 here

The data was then analysed at individual level, giving each participant an average score for engagement, imagination and alignment. Seven of the participants were positioned between the modes of engagement and imagination, two between imagination and alignment, and one between engagement and alignment.

We have summarised briefly the quantitative methods used to analyse our data. Those methods will be explained in more detail in a subsequent technical paper (Sharkey et al, forthcoming).

\section{Findings}

It is evident from the above analysis that the cohort positions itself more towards "engagement" and "imagination" in the Landscape of Practice, and less towards "alignment". Only four of the ten participants chose any "alignment" activity among their top five. More interesting than the positioning of the whole cohort is the positioning of individuals within it, which varies greatly in a way that contradicts the view that doctoral identity development is a simple linear process from practitioner to researcher. 
The findings derived from the quantitative analysis are echoed by the qualitative data collected during the interviews. Here we directly address our research questions, with quotes that are typical of the responses of the student cohort.

Our participants spoke of their positive experience of the peer support network that is one of the stated aims of the programme. This is shown in both their response to the card sort and in their more detailed comments in the interviews:

What l've taken from it is really good critical reviews of my work, from my colleagues on the course. The peer review part has been excellent and that's what's kept me on the course, the other people on the course. (Bethan)

Two-way engagement with others' research and peer review? Actually, quite important, that, because it enabled me to get critique from a colleague who understood more about my narrative that the supervisors would necessarily have done. (Eleanor)

Asked how the programme might be reviewed in order to be more effective in meeting the needs of a diverse cohort of students, participants made specific suggestions about diversity of language and the diversity of the cohort:

One of the big learning curves that I went on as part of the educational doctorate is: I'm a scientist, and I come from a scientific background, and this is social research, and social science. And it was a whole new language for me to learn, and it took me a while to get a handle on some of the terms that we use. (Eleanor) 
I think the idea of there being a continuum between practitioner and academic l'd agree with. My experience of the course is that it puts more emphasis on the academic and values that more, which is quite interesting considering it's a professional doctorate. (Catherine)

\section{How are the identities of professional doctorate students shaped by their pedagogic, discursive and social experiences?}

Here we recorded diametrically opposed responses to the conceptual diagram based on Wenger's modes of identification. Some could immediately relate to it, perhaps self-effacingly:

I completely identify with it (laughs), because I'm totally at the practitioner stage. (Bethan)

It's the unconscious incompetence and the conscious incompetence: as you learn anything new, you go from being in a state of not knowing anything but not knowing you don't know, to passing into that state of "actually I know what I don't know". (Eleanor)

That's the tools to plotting - engagement, that's what the plot is imagination, that's where you put yourself in the plot - alignment. (Greg)

Some found it too simplistic or were unable to engage with it at all:

It's too linear for me ... I think it is an iterative process. (Andrea)

I'm having to employ my empathy here and I think it's because I'm not immersed in the education community. My struggle to relate to this is because I'm kind of cross-discipline. (Diane) 
One participant moved the discussion on from Wenger's three modes of identification ("it's a little bit linear, it's more complex than that") to recognise the implications of Wenger's thinking about boundaries of practice:

We're not doing this, modulation of identification, as an independent body, we are doing it in relation to everybody else, a kind of mini community of practice. So I would say alongside those three, there's something about relationships and communication. Interaction, because even the one-toone tutorials, supervision, it's still a form of developing your identity, through other relationships. (Karen)

The participants reflected on their motivation, the changes that they experienced and the questions that those changes raised for them:

(Colleagues ask) "Why would you spend your weekend doing extra work?" and somebody said this to me the other day, and I can't remember where the quote's from, but it was "life's not about waiting for the storm to pass, it's about learning to dance in the rain", and I suppose one of the reasons that I did the EdD was about that kind of valuing the dancing in the rain, valuing the process. (Karen) The question I'm always going back to and thinking, why am I doing this course and what am I getting out of it? What do I now know? Why has my world become more confusing than it used to be? (Greg) 
The data suggest that participants perceive and respond to the challenges of the EdD in different ways. These differences seem to depend on the personal and professional background of the individual, their local professional context, and their response to the wider discourses which permeate education.

Wenger's social perspective on professional learning $(1998,2010)$ has enabled us to understand in more detail the transitions, adjustments and challenges that doctoral students experience. It is by drawing on his work that we have been able to populate our framework, where the activities of the two-year taught part of the programme are grouped in categories relating to engagement, imagination and alignment. In doing this we have seen that each of the doctoral students on this programme is indeed involved in a number of communities of practice that intersect and interplay. Greg's plaintive "Why has my world become more confusing than it used to be?" locates him at the boundary between a community of practice where prior to the starting the doctorate he was more comfortable, and a new 'EdD' community of practice. It is at these boundaries that ideas, conceptions and thinking are troubled. We suggest that Greg's confusion about his world will eventually result in innovation and new thinking both about his agency and his identity.

\section{Conclusions and further work}

When considering our contribution to knowledge, we make no broad generalisations as we are conscious of the exploratory and small-scale nature of this research: it has 
considered a single group of EdD students at a particular point in their development. We have highlighted the interaction between the structure of the programme and our agency and learning. Our work is significant in its application of Wenger's ideas about a landscape of practice to professional learning or professional doctorates. In doing so, we have developed a methodology where the data collection and analysis are inextricably bound, not just to each other, but also to the conceptual framework of engagement, imagination and alignment which we have developed as the basis of our work. The journey through a professional doctorate is a complex and non-linear process in which individuals shape and are shaped by their journey through the landscape. At this early stage in our project, we have found the theoretical approach based on Wenger to be an effective way of stimulating discussion and shaping our analysis, but less effective in enabling us to theorise on our findings.

Our research also encourages university tutors to reflect on their own structures for supporting the development of early career researchers and their identities. When planning for future cohorts of doctoral students, this research can prompt questions as to how the structure and content of a programme can best support professionals with diverse prior experiences, research interests and preferred approaches.

There are several areas within which we wish to extend this study. Methodologically, we shall develop further the quantitative approach to data analysis, described only briefly in this article, so as to explain and exemplify it more fully. Theoretically, we shall apply to our analysis the thinking of other writers on reflexivity and identity development, contrasting their theories with those of Wenger. As we have suggested, the differences between participants in the ways in which they have 
conceptualised and responded to the "taught" elements of the EdD relate to their social and professional background as well as to local and more distal contexts within which their work and studies are set. Subsequent work will provide an explanatory framework for these differences. Empirically, we would like to study this cohort further. We have begun a series of interviews with the supervisory team and would like to return to our participants when they are at, or close to, the end of their doctoral studies.

While pursuing their individual thesis projects, the authors continue to work as a cooperative group of doctoral students, stimulated and nurtured by the University of Manchester EdD programme.

3600 words

\section{Acknowledgements}

We would like to acknowledge the unfailing support and encouragement of our supervisors as we have developed this project. Helen Gunter and Etienne Wenger have given us invaluable advice on our theoretical approach. Most of all we are grateful to our EdD colleagues for their participation and for the privilege of learning with and from them. 


\section{References}

Barnacle, R. and Newburn, I. (2010), Learning networks and the journey of 'becoming doctor', Studies in Higher Education, 35:4, 433-444

Ellis, B. and Robb, Y. (2014), 'Thank goodness for the cohort!', conference paper, http://www.ukgce.ac.uk/url/ICPD2014_42, accessed 27.06.14

Hall, L.A. and Burns, L.D. (2009), Identity Development and Mentoring in Doctoral Education, Harvard Educational Review, 79:1, 49-70

Hawkes, D. (2014), So who wants to do an EdD anyway? Evidence from the loE EdD 1996-2013, conference paper, http://www.ukgce.ac.uk/url/ICPD2014_19, accessed 27.06.14

Lord, J., Parr, E., Rayner, S. and Sharkey, R. (2014), An investigation into the development of professional doctorate student identities, conference paper, http://www.ukgce.ac.uk/url/ICPD2014_20, accessed 27.06.14

McAlpine, L., Jazvac-Martek, M and Hopwood, N. (2009), Doctoral student experience in education: activities and difficulties influencing identity development, International Journal for Researcher Development, 1:1, 97-109

Mills, E. and Black, P. (2014), Advanced Practice Development and the Professional Doctorate in Pharmacy, conference paper, http://www.ukgce.ac.uk/url/ICPD2014_26, accessed 27.06.14

Pilkington, R. (2014), A subtle game: the interplay of course assessment, outcomes and research for participants studying for a professional doctorate, conference paper, http://www.ukgce.ac.uk/url/ICPD2014_53, accessed 27.06.14

Poultney, V. (2014), Joint supervision: A model for successful doctoral outcomes?, conference paper, http://www.ukgce.ac.uk/url/ICPD2014_07, accessed 27.06.14

Rhodes, C. (2014), The Transformation of Educational Practitioners into Educational Researchers: A View Through a Different Lens, International Studies in Educational Administration, 41:3, 3-18

Sanders, G. (2014), The impact of doctoral studies on individuals and their practice: developing resistance and resilience, conference paper, http://www.ukgce.ac.uk/url/ICPD2014_44, accessed 27.06.14

Sharkey, R., Lord, J, Parr, E. and Rayner, S. (2015), An investigation into the development of professional doctorate student identities, forthcoming

Taylor, A. (2007), Learning to become Researching Professionals: The Case of the Doctorate of Education, International Journal of Teaching and Learning in Higher Education, 19:2, 154-166 
Taylor, J. (2014), The shifting doctoral landscape in Art \& Design: relocating support networks in line with para-academic aspirations, conference paper, http://www.ukgce.ac.uk/url//CPD2014_82, accessed 27.06.14

Wenger, E. (1998) Communities of practice: learning, meaning, and identity, Cambridge: Cambridge University Press

Wenger, E. (2010), Communities of Practice and Social Learning Systems: the Career of a Concept, in Blackmore, C., Social Learning Systems and Communities of Practice, 179-198, Milton Keynes: The Open University 
Table 1: Grouping of activities

\begin{tabular}{|l|l|l|}
\hline Engagement & Imagination & Alignment \\
\hline Taught sessions: as recipient & $\begin{array}{l}\text { Engagement beyond the } \\
\text { local research community }\end{array}$ & $\begin{array}{l}\text { Identifying your epistemic } \\
\text { community }\end{array}$ \\
\hline $\begin{array}{l}\text { Taught sessions: as } \\
\text { participant }\end{array}$ & $\begin{array}{l}\text { Social networking: real and } \\
\text { virtual }\end{array}$ & $\begin{array}{l}\text { Managing your personal } \\
\text { research plan }\end{array}$ \\
\hline $\begin{array}{l}\text { Taught sessions: as } \\
\text { presenter }\end{array}$ & Theory and theorising & Online presence \\
\hline Taught sessions: as critic & $\begin{array}{l}\text { Two-way engagement with } \\
\text { others' research (peer } \\
\text { review) }\end{array}$ & $\begin{array}{l}\text { Positioning yourself within } \\
\text { the research communities }\end{array}$ \\
\hline $\begin{array}{l}\text { One-to-one } \\
\text { tutorial/supervision }\end{array}$ & Writing and reading & Publication \\
\hline eProg/Blackboard & & \\
\hline
\end{tabular}

Table 2: rank order of activities in the opinion of participants

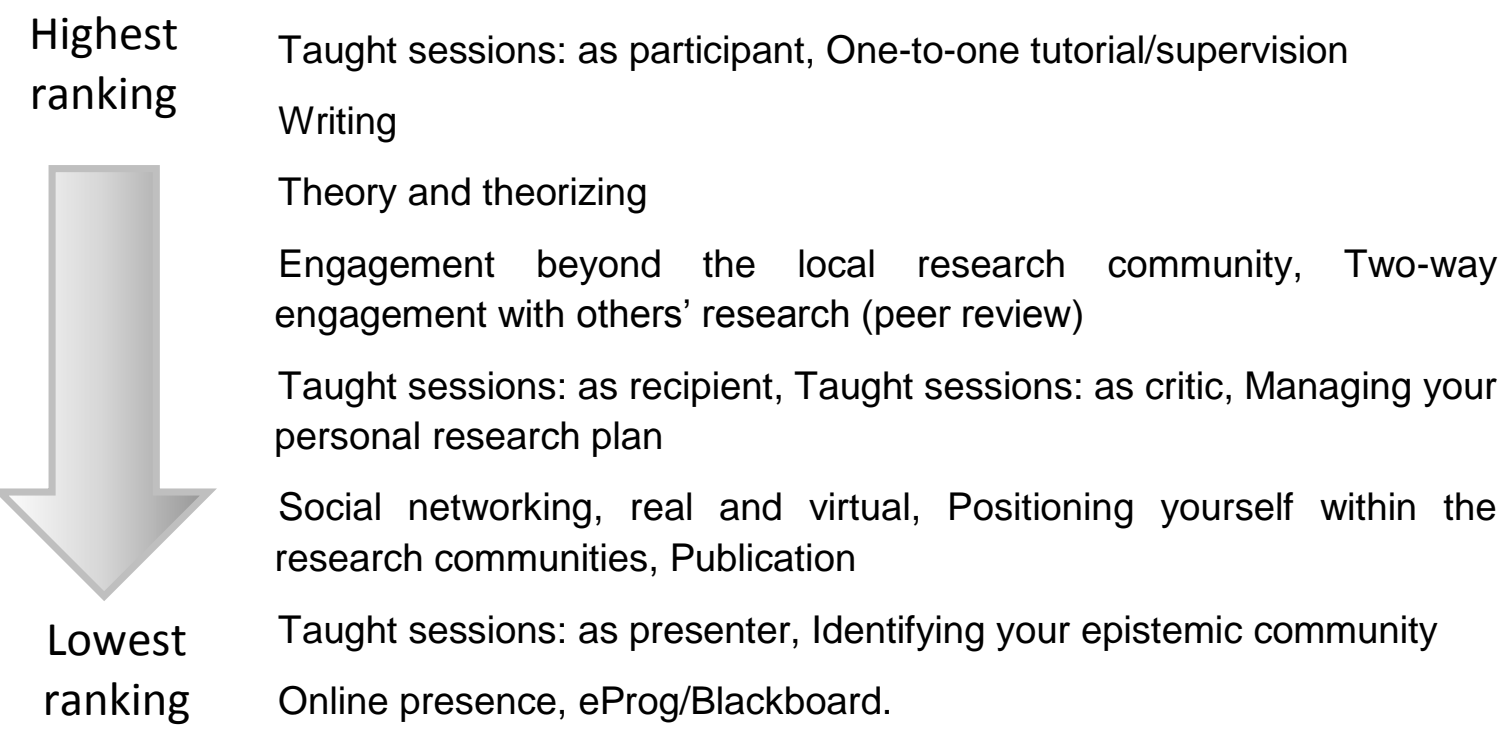

